\title{
Behavior Problems in Children With Specific Language Impairment
}

\author{
Verónica Maggio, SLP, PhD', Nora E. Grañana, MD, PhD ${ }^{1,2}$, \\ Alba Richaudeau, MD, PhD', Silvio Torres, MD', \\ Adrián Giannotti, MD', and Angela M. Suburo, MD, PhD $^{3}$
}

\begin{abstract}
We studied behavior in a group of children with specific language impairment in its 2 subtypes (expressive and mixed receptive/ expressive). After exclusion of other psychiatric conditions, we evaluated II4 children of ages 2 to 7 years using language developmental tests and behavioral screening scales. Behavior problems appeared in $54 \%$ of the children. Withdrawn was the most frequently found syndrome in preschool children, whereas anxious/depressed and social problems were the most frequent in older children. The high frequency of behavioral syndromes in children with specific language impairment is remarkable and requires the awareness of primary attendants and specialists. Anxiety, depression, social isolation, and aggressive and rulebreaking behavior can obscure identification of the language impairment. Taking into account this relationship would improve the chances of a timely and appropriate intervention.
\end{abstract}

\section{Keywords}

language impairment, behavior problems, social behavior, communication, Child Behavior Checklist, Illinois Test of Psycholinguistic Abilities

Received May 12, 2013. Received revised August 28, 2013; September 27, 2013. Accepted for publication September 30, 2013.

Specific language impairment is one of the most important communication problems affecting young children. ${ }^{1}$ Children having this condition show "inadequate language acquisition at the expected age with otherwise ostensibly normal development." 2 Thus, diagnosis is based on a mismatch between language and nonverbal abilities, which disturbs academic achievement or social communication. ${ }^{3,4}$ A similar definition is given by the National Institute on Deafness and Other Communication Disorders, ${ }^{5}$ which acknowledges developmental language disorder, language delay, and developmental dysphasia as alternative names. Specific language impairment is clearly separated from the secondary language impairment that accompanies various conditions displaying frank sensory, cognitive, or neurologic deficits.

Although exact numbers are lacking, specific language impairment seems to be one of the most common childhood learning disabilities. ${ }^{5}$ In the 1990 s, a prevalence of $7 \%$ was shown in preschoolers, ${ }^{6}$ but a more recent review found a median for prevalence of $5.95 \% .^{7}$ A similar figure has been described in Sweden. ${ }^{8}$ By contrast, a prevalence smaller than $1 \%$ for children younger than 6 years has been recently reported in Finland. ${ }^{9}$ Clinical populations of children with specific language impairment show high levels of comorbidity with literacy and behavior disorders. ${ }^{10}$ The coexistence of language impairment and emotional and behavior problems has been recognized by several authors, its rate being estimated at 50\%-70\% ${ }^{11}$ Behavior problems can alert about the magnitude of the communication impairment, but they can also confound the diagnosis with other conditions such as disorders of the autistic spectrum, pragmatic language impairment or attention-deficit hyperactivity disorder (ADHD). As clearly stated more than a decade ago, not every child with language impairment is a misdiagnosed case of autistic disorder. ${ }^{12}$

Because knowledge about the burden of behavior problems could improve attention by primary care physicians, we evaluated these difficulties in a population of consecutive pediatric patients with confirmed specific language impairment. We applied the Child Behavior CheckList ${ }^{13,14}$ after careful exclusion of any other neurologic, psychological, or social deprivation condition. This well-known norm-referenced test assesses

\footnotetext{
' Clínica CLASE de Neuropsicología, Hospital Universitario Austral, Pilar, Argentina

${ }^{2}$ Neurología Infantil, Servicio de Pediatría, Hospital Carlos Durand, Buenos Aires, Argentina

${ }^{3}$ MedicinaCelular y Molecular, Facultad de Ciencias Biomédicas, Universidad Austral, Pilar, Argentina
}

\section{Corresponding Author:}

Nora E. Grañana, MD, PhD, Juncal 2354-PB 3-(I I 25) Buenos Aires, Argentina. Email: ngranana@gmail.com 
Table I. Illinois Test of Psycholinguistic Abilities (ITPA): Subtests Included in This Study.

Visual reception (VR): Measures ability to gain meaning from familiar pictures.

Example: Match picture stimulus with picture from same category.

Auditory association (AA): Measures ability to relate concepts presented orally.

Example: Verbal-analogies test (eg, "Grass is green, sugar is ...").

Visual association (VA): Measures ability to relate concepts presented visually.

Example: Relate a pictorial stimulus to its conceptual counterpart (eg, bone goes with dog).

Grammatical closure (GC): Measures ability to complete a phrase grammatically correct in an automatic way.

Example; the examiner shows 2 pictures and say: "There's one bed here there ... here," to which the child might respond, "There're are two beds here."

emotional (internalizing) and behavioral (externalizing) disorders. ${ }^{15} \mathrm{We}$ also assessed sex ratios for each group, because a preponderance of boys or girls in any of the groups under study might suggest a difference in the etiopathogenesis of the different conditions. ${ }^{16}$ Hand preference, which might be underdeveloped in children with specific language impairment, ${ }^{17}$ was also examined.

\section{Methods and Materials}

We analyzed the clinical histories of children consulting the Clínica de trastornos de Atención, Lenguaje y del Seguimiento Escolar at Hospital Universitario Austral, and a speech pathologist private practice during the period 2008 to 2011. Both centers work with referrals of children with problems of attention, language, or school performance from the same community, a suburban area of medium-high socioeconomic status. Tests used in this study form part of an established routine for children attending these clinics. Our work was carried out under a protocol approved by the Comité de Investigaciones de la Facultad de Ciencias Biomédicas, Universidad Austral, 2009. Only native Spanish-speaking children with a confirmed specific language impairment were included.

Specific language impairment was diagnosed according to the tenets of the International Classification of Diseases-10 (ICD-10). This standard uses a statistical definition and requires an intelligence quotient within normal values, with at least a language test, either expressive or receptive, scoring 2 standard deviations or more below the population mean, that is, below the third percentile. In addition, it stipulates that language skills should be at least 1 standard deviation below that measured for nonverbal skills. ${ }^{18}$

For evaluation of nonverbal intelligence quotient, we used the Wechsler tests for Preschool and Primary Scale of Intelligence (version III, WPPSI III), and the Intelligence Scale for Children (Version IV), ${ }^{19,20}$ the Leiter-R Brief nonverbal intelligence quotient, ${ }^{21}$ the Beery Developmental Test of Visual-Motor Integration, ${ }^{22}$ the McCarthy Scales of Children's Abilities, ${ }^{23}$ and the Visual Construction and Draw-a-Person. ${ }^{24}$ The diagnosis of a specific language impairment requires an intelligence quotient within normal values $100 \pm 15(+1$ and -1 standard deviation). Children showing a developmental delay, that is, nonverbal intelligence quotient below the third percentile, did not receive this diagnosis. The presence of any other concomitant medical, genetic, or neurologic disorder, such as sensory deafness, blindness, a definite diagnosis of autism or any autism spectrum disorder, pragmatic language impairment, or any other neurodevelopmental delay excluded the diagnosis of specific language impairment.

Language evaluation was based on the Gardner's Receptive One Word Picture Vocabulary Test, including 2 subtests: Gardner's Comprehensive Vocabulary and Gardner's Test for Expressive Vocabulary. ${ }^{25,26}$ In addition, we used several subtests of the Illinois Test of Psycholinguistic Abilities, 3rd Ed (ITPA-3) ${ }^{27}$ to clarify the aspects of language that were difficult for a particular child. Examples of these subtests-visual comprehension, visual association, auditive association, and grammatical closure - are shown in Table 1. Impairments were classified as expressive or mixed expressive-receptive. ${ }^{28}$ An expressive specific language impairment was diagnosed when children displayed Gardner's and/or Illinois expressive subtest scores 2 standard deviations or more below the population mean, that is, below the third percentile. By contrast, a mixed expressive-receptive specific language impairment was identified when children displayed receptive subtest scores of 2 standard deviations or more below the population mean.

Behavioral/Emotional problems and competencies were assessed with the Child Behavior Checklist for preschoolers and for children (CBCL/1 $1 / 2-5, \mathrm{CBCL} / 6-18)$, with a questionnaire validated for Latin American populations. ${ }^{29}$ The Preschool Age test for 11/2-5-year-old children uses the 7-syndrome model, including I, emotionally reactive; II, anxious/depressed; III, somatic complaints; IV, withdrawn; V, sleep problems; VI, attention problems; VII, aggressive behavior and other problems. Syndromes I to IV make up the internalizing syndromes, whereas VI and VII add to externalizing syndromes. The test for school-age children (6-18 years) includes I, anxious/depressed; II, withdrawn/depressed; III, somatic complaints; IV, social problems; V, thought problems; VI, attention problems; VII, rule-breaking behavior; VIII, aggressive behavior and other problems. Internalizing syndromes comprise groups I, II, and III, whereas VII and VIII represent the externalizing syndromes. For each problem class, children above the 93th percentile were scored as positive.

\section{Statistics}

The hypothesis under evaluation was that a significant proportion of children with specific language impairment presented behavior problems. Therefore, we used simple descriptive statistics to evaluate their frequency. As a secondary hypothesis, we tested whether different types of language impairment correlated with different frequencies or types of behavioral problem. Results were expressed as mean \pm standard error, or median (lower and upper $95 \%$ confidence interval). We used 2-tailed tests, and a 95\% confidence interval was considered acceptable. Calculations were made with GraphPad Prism (GraphPad Software, San Diego, CA, www.graphpad.com).

\section{Results}

\section{Language Impairment Diagnosis}

Low scores in any one of the language tests would suffice to diagnose language impairment. However, most children showed 2 positive expressive tests. The agreement between the Gardner's test for expressive vocabulary and the Illinois Grammatical Closure was $84 \%$ in the expressive group and $92 \%$ in the mixed (expressive-receptive) Group (Table 2). In the mixed 
Table 2. Children Failing the Different Expressive Tests.

\begin{tabular}{lccc}
\hline & $\begin{array}{l}\text { Gardner's } \\
\text { test for } \\
\text { expressive } \\
\text { vocabulary }\end{array}$ & $\begin{array}{c}\text { Gramm- } \\
\text { atical } \\
\text { closure }\end{array}$ & $\begin{array}{c}\text { Gardner's } \\
\text { Test and } \\
\text { grammatical } \\
\text { closure }\end{array}$ \\
\hline $\begin{array}{l}\text { Expressive impairment } \\
\text { Infant }(\mathrm{n}=\mathrm{II})\end{array}$ & 11 & 10 & 10 \\
Kindergarten age $(\mathrm{n}=2)$ & 2 & 2 & 2 \\
School age $(\mathrm{n}=6)$ & 5 & 5 & 4 \\
Mixed impairment & & & \\
Infant $(\mathrm{n}=32)$ & 31 & 32 & 31 \\
Kindergarten age $(\mathrm{n}=43)$ & 39 & 42 & 38 \\
School age $(\mathrm{n}=20)$ & 19 & 18 & 17 \\
\hline
\end{tabular}

group, most reception difficulties were identified by the Illinois Auditive Association test, which was positive in $94 \%$ of the affected children. There was high agreement between the various tests (Table 3), and most children scored positive in 2 to 3 tests $(42 \%)$, or in all 4 of them (46\%).

\section{Characterization of the Population}

We identified 114 children with a specific language impairment. Their ages ranged from 2.1 to 7.9 years $(4.7 \pm 0.1$ years). Girls and Boys showed similar age distributions, $5.2 \pm 0.3$ and $4.5 \pm 0.1$ years, respectively. Taking into account developmental milestones and the behavior checklists, we considered 3 age groups: infant (2-3 years), Kindergarten ( $4-5$ years), and school (6-7 years) (Table 4). Affected children of school age were less numerous than preschool children. This was to be expected, because language impairment is usually diagnosed at an early age.

The sex ratio indicated a predominance of affected boys over affected girls (Table 4$)$. Infant children showed a much higher sex ratio than Kindergarten and school-age children $\left(\chi^{2}\right.$ for trend, $P<.05)$. Right lateralization was absent in $47 \%$ of the children included in this study. Differences of dexterity between age groups were not statistically significant (Table 4).

About $17 \%$ of the children had an expressive specific language impairment. No significant differences in age or sex ratio of children were detected between these children and those having a mixed impairment (Table 4). Most children with an expressive specific language impairment diagnosis appeared in the infant group, whereas the mixed cases clustered in the Kindergarten group. This difference of proportions was statistically significant $\left(\chi^{2}, P<.02\right)$.

\section{Behavior Problems}

About half of the children displayed behavior problems (Tables 5 and 6). This proportion was found in all age groups and could not be correlated with the presence of an expressive or a mixed impairment. No demographic differences could be detected between children with and without problems (Table 6). Moreover, both groups showed the same predominance of boys over girls and similar proportions of nondexterity. Affected boys and girls displayed the same burden of problems: 2.25 problems per girl and 2.48 for boys.

As shown in Table 7, $80 \%$ of the preschoolers with behavior problems showed internalizing syndromes. Withdrawn was the most frequently found syndrome, appearing in $65 \%$ of children with problems. Syndromes of the externalizing domain only occurred in $57 \%$ of children with behavior problems. Children displaying more than 3 syndromes were often found. These highly troubled children usually displayed withdrawn in various combinations with emotionally reactive, attention problems, or aggressive behavior.

Internalizing problems were also the most frequently found problem in children of school age (Table 7). In this group, anxious/depressed syndrome showed in $50 \%$ of the affected children. Social issues, withdrawn/depressed, and rulebreaking behavior were also present.

Complexity of the behavioral difficulties, as reflected by the number of syndromes detected in each affected child, was higher in the mixed $(2.67 \pm 0.28$ syndromes/child) than in the expressive group $(1.50 \pm 0.38$ syndromes/child, MannWhitney test, $P<.05$ ).

Behavior problems could be a consequence of communication difficulties. If this were the case, more behavior problems should be found in those children that failed in a larger number of language subtests. To test this hypothesis, we looked for associations between the number of behavior problems per child and the number of failed receptive Illinois subtests in preschool children with a mixed language impairment. We did not observe any correlation between the number of failed Illinois subtests and the number of behavioral syndromes. Many children with difficulties in the 3 receptive subtests remained free of behavior problems, whereas about $70 \%$ of the children showed deficits in 3 receptive tests, irrespective of their behavioral burden (Figure 1).

\section{Discussion}

We have evaluated a sample of children with specific language impairment who attended our clinic for diagnostic purposes. Because disruptive or withdrawn manners frequently appeared as an important or even the main reason for consultation, we evaluated the importance of behavior problems in this selected sample. In addition, we investigated possible associations between the characteristics of the language impairment and the quality and load of these behavior problems. Our study, based on the Child Behavior Checklist (Achenbach's test), showed that these problems appeared in about half of the children with specific language impairment.

\section{Prevalence of Behavioral Difficulties in Children With Specific Language Impairment}

It must be stressed that the importance of social withdrawal and other behavior problems has been well established for children with language impairment associated to neurodevelopmental delay, such as low intelligence quotient or neurologic insult 
Table 3. Number of Children Failing the Different Receptive Tests.

Gardner's Comprehensive Vocabulary Visual comprehension Visual association Auditive association All tests

\begin{tabular}{lrrrrr}
\hline Infant $(\mathrm{n}=32)$ & 27 & 28 & 30 & 31 \\
Kindergarten age $(\mathrm{n}=43)$ & 30 & 23 & 29 & 41 \\
School age $(\mathrm{n}=20)$ & 12 & 4 & 6 & 17 & 3 \\
\hline
\end{tabular}

Table 4. Characteristics of Children With Specific Language Impairment.

\begin{tabular}{lcccc}
\hline & \multicolumn{4}{c}{ Age } \\
\cline { 2 - 4 } & Infant & Kindergarten & School & Total \\
\hline $\mathrm{N}$ & 43 & 45 & 26 & 114 \\
Age & & & & \\
$\quad$ Range & $2.1-3.9$ & $4.0-5.8$ & $6.0-7.9$ & $2.1-7.9$ \\
Median & 3.1 & 4.9 & 7.0 & 4.6 \\
Mean & 3.2 & 4.9 & 6.8 & 4.7 \\
Standard error & 0.1 & 0.1 & 0.1 & 0.1 \\
Dexterity & & & & \\
Yes & 18 & 26 & 16 & 60 \\
$\quad$ No & 25 & 19 & 10 & 54 \\
Sex ratio & 6.7 & 3.8 & 1.9 & 3.8 \\
Boys & 37 & 36 & 17 & 90 \\
$\quad$ Girls & 6 & 9 & 9 & 24 \\
Specific language & & & & \\
impairment & & & & \\
$\quad$ Expressive & 11 & 2 & 6 & 19 \\
$\quad$ Mixed & 32 & 43 & 20 & 95 \\
\hline
\end{tabular}

(reviewed by Rescorla et $\mathrm{al}^{30}$ ). However, the association of specific language impairment with behavior difficulties has not yet been established, because available studies have diverse results. An early study of children with specific language impairment showed that their behavior scores (Total Behavior Problems) were not in the clinical range of the Achenbach's test; however, they were significantly greater than those from age peers with typical language development. ${ }^{31}$ Authors suggested that these behavior problems would most likely represent an emotional response. Behavior and social difficulties, though not necessarily within the clinical range, might be more evident in languageimpaired children from low-income families. ${ }^{32}$

On the other hand, several studies carried out in children attending schools for the language and hearing impaired showed clinically significant behavior problems in children with specific language impairment: $23 \%$ of a sample $(\mathrm{n}=$ 56) of school-age children, ${ }^{33} 30 \%$ of a large sample $(\mathrm{n}=71)$ of 5-year-old children, ${ }^{34}$ and $18 \%$ of a smaller sample $(\mathrm{n}=$ 38 ) of children between 2.5 and 5.5 years. ${ }^{35}$ Studies in toddlers (up to 30-35 months of age) did not show a strong relationship between language delays and behavioral/emotional problems, leading to the suggestion that these difficulties only affected older children. ${ }^{30}$ Remarkably, some of these studies concluded that behavior problems were associated with the inclusion of children with neurodevelopmental delay or autism spectrum disorders. ${ }^{30,31}$ Other recent studies have used the Strengths and
Table 5. Behavioral Problems in Children With Specific Language Impairment.

\begin{tabular}{lrrrr}
\hline & \multicolumn{4}{c}{ Age } \\
\cline { 2 - 5 } & Infant & Kindergarten & School & All ages \\
\hline Expressive impairment & 11 & 2 & 6 & 19 \\
With problems & 5 & 0 & 3 & $42 \%$ \\
Without problems & 6 & 2 & 3 & $58 \%$ \\
Mixed impairment & 32 & 43 & 20 & 94 \\
With problems & 19 & 23 & 11 & $55 \%$ \\
Without problems & 13 & 20 & 9 & $45 \%$ \\
\hline
\end{tabular}

Table 6. Characteristics of Language Impaired Children With and Without Behavioral Problems.

\begin{tabular}{|c|c|c|c|c|c|c|}
\hline \multirow[b]{2}{*}{ Group } & \multirow[b]{2}{*}{ Problems } & \multirow[b]{2}{*}{$\mathrm{n}$} & \multicolumn{3}{|c|}{ Age } & \multirow[b]{2}{*}{ Standard error } \\
\hline & & & Range & Median & Mean & \\
\hline \multicolumn{7}{|l|}{ Infant } \\
\hline & With & 24 & $2.1-3.9$ & 3.1 & 3.2 & 0.1 \\
\hline & Without & 19 & $2.6-3.9$ & 3.2 & 3.3 & 0.1 \\
\hline \multicolumn{7}{|c|}{ Kindergarten } \\
\hline & With & 23 & $4.0-5.7$ & 5.0 & 4.9 & 0.1 \\
\hline & Without & 22 & $4.0-5.8$ & 4.9 & 4.8 & 0.1 \\
\hline & With & 14 & 6.2-7.I & 6.9 & 6.8 & 0.1 \\
\hline & Without & 12 & $6.0-7.9$ & 6.9 & 6.8 & 0.2 \\
\hline
\end{tabular}

Difficulties Questionnaire, which evaluates behavioral, emotional and social difficulties. In the conduct subscale, fewer problems occurred at age 16 than at ages 7-8, whereas problems in the peers subscale increased over time. ${ }^{36}$ As in the previous studies, however, the mean scores did not reach clinical levels of difficulty. Nevertheless, substantial peer problems have been found in a group of 16-year-old youngsters with specific language impairment. ${ }^{37}$

Our figures for the coexistence of behavioral difficulties and specific language impairment were, in average, larger than those in previous reports. Moreover, we found almost the same proportion of children with and without problems in the different age groups - infant, Kindergarten, and school—suggesting that these problems would be intrinsic to the language impairment and not a reactive effect. Remarkably, the largest proportion of behavior problems appeared in the infant group. Although these figures might not represent the prevalence of behavior problems in the general population of children with specific language impairment, they certainly demonstrate the existence of this association and its relevance for diagnosis and treatment. 
Table 7. Behavioral Syndromes ${ }^{\mathrm{a}}$ Found in Children of Preschool Age.

\begin{tabular}{|c|c|c|c|c|c|c|c|c|c|c|}
\hline \multirow[b]{2}{*}{$\begin{array}{l}\text { Children with } \\
\text { behavior problems }\end{array}$} & \multicolumn{7}{|c|}{$\begin{array}{l}\text { Number of syndromes in the expressive } \\
\text { and mixed subpopulations }\end{array}$} & \multicolumn{2}{|c|}{$\begin{array}{l}\text { Number of children with } \\
\text { syndromes }\end{array}$} & \multirow[b]{2}{*}{$\begin{array}{l}\text { Syndromes/ } \\
\text { child }\end{array}$} \\
\hline & $\begin{array}{l}\text { Emotionally } \\
\text { reactive }\end{array}$ & $\begin{array}{l}\text { Anxious/ } \\
\text { depressed }\end{array}$ & $\begin{array}{l}\text { Somatic } \\
\text { complaints }\end{array}$ & Withdrawn & $\begin{array}{l}\text { Sleep } \\
\text { problems }\end{array}$ & $\begin{array}{l}\text { Attention } \\
\text { problems }\end{array}$ & $\begin{array}{l}\text { Aggressive } \\
\text { behavior }\end{array}$ & Internalizing & Externalizing & \\
\hline $\begin{array}{l}\text { Expressive }(n=6) \\
\text { Mixed }(n=4 I) \\
\text { All }(n=47)\end{array}$ & $\begin{array}{r}0 \\
15 \\
15\end{array}$ & $\begin{array}{r}3 \\
9 \\
12\end{array}$ & $\begin{array}{r}1 \\
9 \\
10\end{array}$ & $\begin{array}{r}2 \\
28 \\
30\end{array}$ & $\begin{array}{l}1 \\
7 \\
8\end{array}$ & $\begin{array}{r}2 \\
15 \\
17\end{array}$ & $\begin{array}{r}2 \\
17 \\
19\end{array}$ & $\begin{array}{r}5 \\
35 \\
40\end{array}$ & $\begin{array}{r}2 \\
25 \\
27\end{array}$ & $\begin{array}{l}1.8 \\
2.4 \\
2.4\end{array}$ \\
\hline
\end{tabular}

${ }^{a}$ Columns showing internalizing and externalizing problems are painted in dark and pale gray, respectively.

Table 8. Behavioral Syndromes ${ }^{\mathrm{a}}$ Found in Children of School Age.

\begin{tabular}{|c|c|c|c|c|c|c|c|c|c|c|c|}
\hline \multirow[b]{2}{*}{$\begin{array}{l}\text { Children with } \\
\text { behavior } \\
\text { Problems }\end{array}$} & \multicolumn{8}{|c|}{ Number of syndromes in the population } & \multicolumn{2}{|c|}{$\begin{array}{l}\text { Number of children with } \\
\text { syndromes }\end{array}$} & \multirow[b]{2}{*}{$\begin{array}{l}\text { Syndromes/ } \\
\text { child }\end{array}$} \\
\hline & $\begin{array}{l}\text { Anxious/ } \\
\text { depressed }\end{array}$ & $\begin{array}{l}\text { Withdrawn/ } \\
\text { depressed }\end{array}$ & $\begin{array}{l}\text { Somatic } \\
\text { complaints }\end{array}$ & $\begin{array}{l}\text { Social } \\
\text { problems }\end{array}$ & $\begin{array}{l}\text { Thought } \\
\text { problems }\end{array}$ & $\begin{array}{l}\text { Attention } \\
\text { problems }\end{array}$ & $\begin{array}{l}\text { Rule- } \\
\text { breaking } \\
\text { behavior }\end{array}$ & $\begin{array}{l}\text { Aggressive } \\
\text { behavior }\end{array}$ & Internalizing & Externalizing & \\
\hline Expressive $(n=3)$ & I & 0 & I & 0 & 0 & 0 & I & 0 & 2 & I & 1.0 \\
\hline Mixed $(n=I I)$ & 6 & 3 & 2 & 5 & I & 2 & 3 & 2 & 8 & 4 & 2.2 \\
\hline All $(n=13)$ & 7 & 4 & 2 & 5 & I & 2 & 4 & 2 & 10 & 5 & 1.9 \\
\hline
\end{tabular}

${ }^{\mathrm{a} C}$ Columns showing internalizing and externalizing problems are painted in dark and pale gray, respectively.

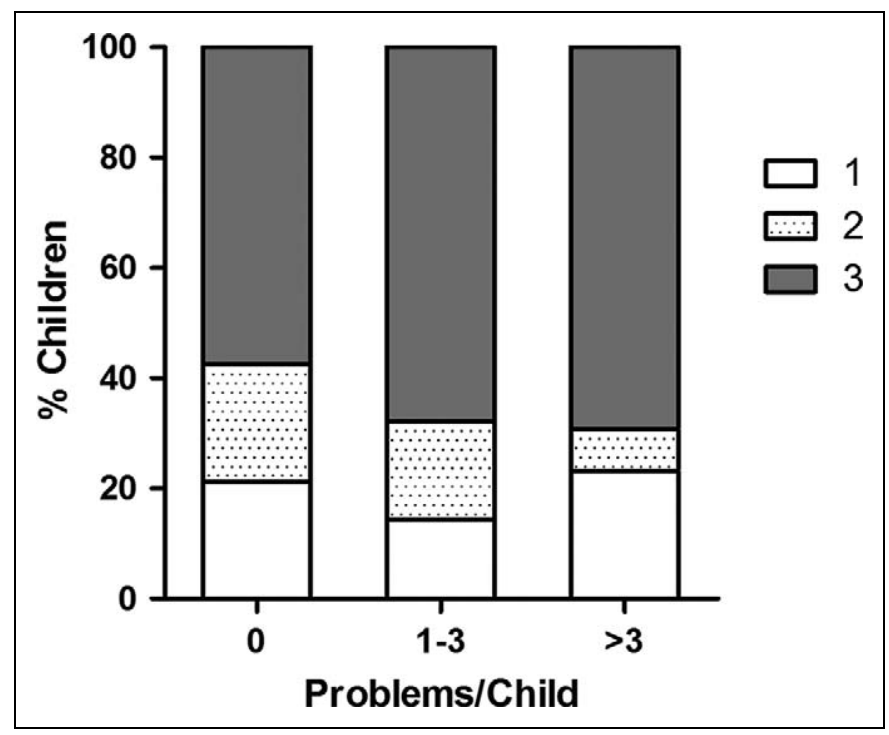

Figure I. Bars correspond to preschool children with a mixed specific language impairment. Children were subdivided into 3 subgroups according to the number of behavior problems, $0,1-3$, and $>3$. Stacks refer to the number of failed Illinois subtests per child. The graph illustrates the lack of correlation between the burden of behavior problems and the extension of the language impairment.

\section{The Nature of Behavior Problems Associated to Specific Language Impairment}

Internalizing problems almost duplicated externalizing problems in children of preschool age as well as in older children. The most frequently found syndromes in preschool children were withdrawn and aggressive behavior. In children of school age, the highest frequency corresponded to anxious/depressed and social problems together with rule-breaking behavior. In general, the behavior problems of children with specific language impairment resembled those expected in autism spectrum disorders ${ }^{38}$ or attention-deficit hyperactivity disorder. ${ }^{39}$ Further studies are required to evaluate the stability of these syndromes over time and their possible association to biological markers that could indicate their etiology.

There is no consensus about the predominance of internalizing or externalizing syndromes in children with specific language impairment. Some studies have found internalizing syndromes as the most frequent problems, ${ }^{11,33}$ whereas others have reported that the highest frequency corresponded to externalizing syndromes. ${ }^{40}$ At least one study reported that internalizing syndromes had the same frequency as externalizing ones. ${ }^{34}$ Internalizing syndromes (Teacher Behavior Rating Scale; reticence and solitary-passive withdrawal) have also been recorded as the most frequent problems in a school sample $(\mathrm{n}=41)$. Comparison with studies based on other behavioral scales ${ }^{41}$ is more difficult.

\section{Behavior Problems and Neurodevelopmental Domains}

As previously acknowledged, ${ }^{33}$ not all children had behavioral difficulties, suggesting that the relationship of these problems with language impairment is not linear and that behavior could be influenced by other-still unknown - variables. Conceivably, specific language impairment with behavior problems might represent a different condition from the impairment without such problems. At the present time, however, there are no clues about the underlying neurobiological mechanisms.

Hand preference was carefully evaluated because it might be related to the asymmetric development of the brain 
hemispheres underlying language maturation. ${ }^{42-44}$ Moreover, functional MRI has recently shown that children with specific language impairment exhibit a significant lack of left lateralization in all core language regions. ${ }^{45}$ Handedness has been associated to intellectual, motor, temperament, and behavioral status, and moreover, evidence supports the existence of intrauterine and neonatal pathological mechanisms, other than brain damage, leading to left hand preference. ${ }^{46}$ Likewise, several studies have reported higher rates of specific language impairment among males than among females. ${ }^{7,16}$ Recent measurements of testosterone in cord blood show a correlation of hormonal levels with increased risk of specific language impairment in boys and decreased risk in girls. ${ }^{47}$ On the other hand, studies recruiting cases from the general population reported similar proportions of boys and girls, ${ }^{6}$ and it has been suggested that the increased male prevalence could reflect the fact that boys attract the attention of parents and teachers more than girls. ${ }^{48}$

In the children included in our study, hand preference and sex ratios were different from the standard patterns. Almost half of our population lacked right hand preference. A large proportion of nondexterity (58\%) appeared in infants, but it was also found in $38 \%$ of the school-age children. Thus, it cannot be attributed to lack of maturation. Remarkably, the sex ratio was 6.7 in infants and 1.9 in children of school age (boys to girls). The higher sex ratio of infants compared to that of older children probably implies that language impairment became evident earlier in boys than in girls.

We found the same burden of behavior problems in boys and girls, suggesting that the male prevalence would not depend on the different attention elicited by boys and girls. ${ }^{48}$ Because hand preference and sex ratios were similar in children with and without behavior problems, the causes of these difficulties must be sought in other, still unidentified developmental domains.

\section{Behavior Problems in Expressive and Receptive/ Expressive (Mixed) Specific Language Impairment}

Only $17 \%$ of the children in our population displayed an expressive language impairment. A similar proportion $(20 \%)$ was also found in a sample of ages 3.5-9.5 years $(n=86){ }^{49}$ A larger proportion (30\%) was described in a school sample $\left(n=41\right.$, ages 6-13 years). ${ }^{41}$ Probably, much larger samples would be required to evaluate the prevalence in the general population. In our study, most children with an expressive impairment belonged to the infant age group. About $34 \%$ of the children in the infant group had an expressive impairment, as in another large sample $(n=103)$ of children aged 18-35 months. ${ }^{30}$ In all these groups, the predominance of children with a mixed impairment contrasts with the predominance of expressive impairment described in the Diagnostic and Statistical Manual of Mental Disorders, Fourth Edition. To our knowledge, there is no justification for this phenomenon. However, comparison of the available evidence and our own results allows speculating that higher mixed/expressive ratios might be found in the clinical setting than in the general population.
A similar explanation has been given to account for the heritability of specific language impairment in different scenarios. ${ }^{50}$

Behavior problems were found in $42 \%$ of children with an expressive impairment and in $55 \%$ of children with a mixed impairment, a not statistically significant difference. However, children with a mixed impairment displayed more clinical syndromes, indicating a higher complexity of their behavioral disorder. Several studies have indicated that children with receptive difficulties are more likely to have social and behavioral difficulties than those with only expressive problems. ${ }^{51,52}$ Within the receptive group, however, we could not find any correlation between behavior problems and specific language deficits. These associations, however, have been identified by other investigators. Girls with more severe receptive problems appear with higher levels of solitary-passive withdrawal than girls with less severe language problems. ${ }^{41}$ By contrast, children with less severe receptive language impairment exhibit more sociable behavior than their peers with more severe impairment. ${ }^{41}$

\section{Communication Problems as the Basis for Behavioral difficulties}

Association of specific language impairment with behavior problems has been explained in several ways. Classical descriptions include limited information processing as a cause of difficulties in language learning and social communication; rejection from others, including their peers, that might result in limited opportunities for social learning; and primary deficits in the social cognition domain that would translate into oral language. $^{53}$

Two frameworks (or models) have been proposed to understand the relationship between the language impairment and the behavioral comorbidities: the Social Adaptation Model considers that behavior problems of language-impaired children reflect social adaptations to their language limitations. The second model, the Social Deviance Model, considers that differences between children with language impairment and nonaffected children reflect differences in the underlying traits that guide children's socioemotional development. ${ }^{11}$ These authors studied a small sample $(\mathrm{n}=17)$ and found a large proportion of children showing behavior problems at a clinical level. Because parents and teachers gave different behavioral ratings, they favored the Social Adaptation Model. ${ }^{11}$ In our study, the lack of association between behavior and biological markers such as handedness and sex supports this hypothesis.

Adolescents with an earlier story of specific language impairment display receptive language problems together with emotional health difficulties. ${ }^{54}$ Moreover, those with emotional problems at 7 years of age also have increased anxiety at 16 years. Authors suggested, however, that behavior problems would not be a direct result of impoverished communicative experiences. ${ }^{54}$ In consonance with these findings, our observation of the same frequency of behavior problems in the infant age as in children of Kindergarten and school age suggests the involvement of developmental factors unrelated to social 
environment. Because we can assume that rejection and intolerance would increase in the Kindergarten and school years, and without denying the importance of the social environment, our data suggest that rejection would not be the sole explanation of behavior problems.

\section{Association and Differential Diagnosis With Other Nosological Entities}

A diagnosis of specific language impairment can be hindered by other possibly related impairments. One of them is late language emergence, a condition of significant delay in language development that is observed in about $19 \%$ of 2 -year-olds. ${ }^{55}$ Many "late talkers" will normalize their language skills by 3-4 years, although some might still show some language impairment during adolescence. ${ }^{56}$

Language impairment seems to be a key feature of autism and, vice versa, autism has some remarkable similarities to language problems in specific language impairment. Previous studies have evidenced that autism-like symptoms, such as poor social relations, aloofness, affectless behavior, and unusual responses to stimuli, appear in about half of the children with persistent language difficulties. ${ }^{57-60}$ Moreover, some studies suggest that children who present with autism spectrum disorders and attention-deficit hyperkinetic disorder have a similar neuropsychological and early language development profile as children who present with a suspicion of early preschool language delay and are shown at school age to have autism spectrum disorders or attention-deficit hyperactivity disorder. ${ }^{61}$ Although similarities might suggest a common pathogenesis, these are different clinical entities. Children with an autistic spectrum disorder with language impairment display weaker functional communication and more severe receptive language difficulties than children with specific language impairment. ${ }^{12,62}$ However, these conditions might recognize a common neural substrate. ${ }^{63}$

\section{Conclusions}

Behavior problems were highly prevalent in specific language impairment-affected children; they were equally frequent in children of infant age as in older children. Moreover, children with an expressive disorder displayed behavior problems as often as those children with a mixed impairment. Withdrawn was the most frequently found behavior problem in younger children, whereas children of school age usually displayed anxious/depressed and social problems.

Professionals and caregivers should be aware of these behavior problems: first, because they further reduce the quality of life of more than half of children with specific language impairment and their families; second, because in some children they might serve as an alert for an early diagnosis; and third, because they might induce an autism spectrum disorders misdiagnosis, as they often include isolation, social problems, and even rule-breaking behavior.
The need for screening of speech and language delay in primary care practice has already been emphasized. ${ }^{64}$ Our findings further stress that language impairments should be methodically explored to discriminate specific language impairment from other pathologies, particularly when they are accompanied by behavior problems. It is important for caregivers and others to be aware of this relationship in order to consider appropriate assessment of children referred for language impairment and to advocate for appropriate early intervention.

\section{Author Contributions}

VM assessed the language and wrote the manuscript. NEG developed the hypotheses, led the clinical team, and wrote the manuscript. AR performed neuropsychological assessment of patients. ST analyzed the data. AG performed clinical and behavioral assessment of patients. AMS analyzed data and wrote the manuscript.

\section{Declaration of Conflicting Interests}

The authors declared no potential conflicts of interest with respect to the research, authorship, and/or publication of this article.

\section{Funding}

The authors received no financial support for the research, authorship, and/or publication of this article.

\section{Ethical Approval}

This work was approved by Comité de Investigaciones de la Facultad de Ciencias Biomédicas, Universidad Austral.

\section{References}

1. Rapin I. Preschool Children With Inadequate Communication. London: Mac Keith Press; 1996.

2. Rapin I. Understanding childhood language disorders. Curr Opin Pediatr. 1998;10:561-566.

3. Bishop DV. The underlying nature of specific language impairment. J Child Psychol Psychiatry. 1992;33:3-66.

4. American Psychiatric Association. Diagnostic and Statistical Manual of Mental Disorders, Fourth Edition (Text Revision). Washington, DC: American Psychiatric Association; 2000.

5. National Institute on Deafness and Other Communication Disorders. Specific language impairment. 2013; http://www.nided.nih. gov/health/voice/Pages/specific-language-impairment.aspx. Accessed July 08, 2013.

6. Tomblin JB, Records NL, Buckwalter P, Zhang X, Smith E, O'Brien M. Prevalence of specific language impairment in Kindergarten children. J Speech Lang Hear Res. 1997;40:1245-1260.

7. Law J, Boyle J, Harris F, Harkness A, Nye C. Prevalence and natural history of primary speech and language delay: findings from a systematic review of the literature. Int J Lang Commun Disord. 2000;35:165-188.

8. Miniscalco C, Westerlund M, Lohmander A. Language skills at age 6 years in Swedish children screened for language delay at 21/2 years of age. Acta Paediatr. 2005;94:1798-1806.

9. Hannus S, Kauppila T, Launonen K. Increasing prevalence of specific language impairment (SLI) in primary healthcare of a Finnish town, 1989-99. Int J Lang Commun Disord. 2009;44:79-97. 
10. Law J, Tomblin JB, Zhang X. Characterizing the growth trajectories of language-impaired children between 7 and 11 years of age. J Speech Lang Hear Res. 2008;51:739-749.

11. Redmond SM, Rice ML. The socioemotional behaviors of children with SLI: social adaptation or social deviance? J Speech Lang Hear Res. 1998;41:688-700.

12. Bishop DV, Norbury CF. Exploring the borderlands of autistic disorder and specific language impairment: a study using standardised diagnostic instruments. J Child Psychol Psychiatry. 2002; 43:917-929.

13. Achenbach TM, Rescorla LA. Manual for the ASEBA Preschool Forms \& Profiles. Burlington, VT: University of Vermont, Research Center for Children, Youth, \& Families; 2000.

14. Achenbach TM, Rescorla LA. Manual for the ASEBA School-Age Forms \& Profiles. Burlington, VT: University of Vermont, Research Center for Children, Youth \& Families; 2001.

15. Pandolfi V, Magyar CI, Dill CA. Confirmatory factor analysis of the Child Behavior Checklist 1.5-5 in a sample of children with autism spectrum disorders. J Autism Dev Disord. 2009;39:986-995.

16. Whitehouse AJ. Is there a sex ratio difference in the familial aggregation of specific language impairment? A meta-analysis. J Speech Lang Hear Res. 2010;53:1015-1025.

17. Bishop DV. Handedness and specific language impairment: a study of 6-year-old twins. Dev Psychobiol. 2005;46:362-369.

18. World Health Organization. The ICD-10 Classification for Mental and Behavioral Disorders: Diagnostic Criteria for Research. Geneva: World Health Organization; 1992.

19. Weschler D. Escala de Inteligencia infantil Weschler. WPPSI III: Paidós; 2002.

20. Weschler D. Escala de inteligencia WISC IV. Buenos Aires: Paidós; 2010.

21. Roid G, Miller L. Escala manipulativa internacional Leiter. Madrid: Editorial Psymtec; 2006.

22. Beery K. VMI, prueba Beery-Buktenica del desarrollo de la integración visomotriz. México: Editorial Manual Moderno; 2000.

23. Mc Carthy D. MSCA. Escalas Mc Carthy de aptitudes y psicomotricidad para niños. Madrid: TEA ediciones; 1972.

24. Casullo M. El test gráfico del dibujo de la figura humana. Normas regionales. Buenos Aires: Editorial Guadalupe; 1998.

25. Gardner MF, Morrison F. Test Figura/Palabra de vocabulario expresivo. Manual y láminas. Buenos Aires: Editorial Médica Panamericana; 1987a.

26. Gardner MF, Morrison F. Test Figura-palabra de vocabulario receptivo: manual y láminas. Buenos Aires: Editorial Médica Panamericana; $1987 b$.

27. Kirk S, Mc Carthy J, Kirk W. Test Illinois de aptitudes psicolinguiśsicas ITPA. Madrid: Editorial TEA; 2004.

28. López-Ibor Aliño JJ, Valdés Miyar M. Manual diagnóstico y estadístico de los trastornos mentales. Texto revisado. Barcelona: Masson; 2002.

29. Viola L, Garrido G, Rescorla L. Testing multicultural robustness of the Child Behavior Checklist in a national epidemiological sample in Uruguay. J Abnorm Child Psychol. 2011;39:897-908.

30. Rescorla L, Ross GS, McClure S. Language delay and behavioral/ emotional problems in toddlers: findings from two developmental clinics. J Speech Lang Hear Res. 2007;50:1063-1078.
31. Benasich AA, Curtiss S, Tallal P. Language, learning, and behavioral disturbances in childhood: a longitudinal perspective. $J \mathrm{Am}$ Acad Child Adolesc Psychiatry. 1993;32:585-594.

32. Qi CH, Kaiser AP. Problem behaviors of low-income children with language delays: an observation study. J Speech Lang Hear Res. 2004;47:595-609.

33. Coster FW, Goorhuis-Brouwer SM, Nakken H, Spelberg HC. Specific language impairments and behavioural problems. Folia Phoniatr Logop. 1999;51:99-107.

34. van Daal J, Verhoeven L, van Balkom H. Behaviour problems in children with language impairment. J Child Psychol Psychiatry. 2007;48:1139-1147.

35. Keegstra AL, Post WJ, Goorhuis-Brouwer SM. Behavioural problems in young children with language problems. Int $J$ Pediatr Otorhinolaryngol. 2010;74:637-641.

36. St Clair MC, Pickles A, Durkin K, Conti-Ramsden G. A longitudinal study of behavioral, emotional and social difficulties in individuals with a history of specific language impairment (SLI). $J$ Commun Disord. 2011;44:186-199.

37. Lindsay G, Dockrell JE. Longitudinal patterns of behavioral, emotional, and social difficulties and self-concepts in adolescents with a history of specific language impairment. Lang Speech Hear Serv Sch. 2012;43:445-460.

38. Duarte CS, Bordin IA, de Oliveira A, Bird H. The CBCL and the identification of children with autism and related conditions in Brazil: pilot findings. J Autism Dev Disord. 2003;33:703-707.

39. Biederman J, Petty CR, Day H, et al. Severity of the aggression/ anxiety-depression/attention Child Behavior Checklist profile discriminates between different levels of deficits in emotional regulation in youth with attention-deficit hyperactivity disorder. J Dev Behav Pediatr. 2012;33:236-243.

40. Tomblin JB, Zhang X, Buckwalter P, Catts H. The association of reading disability, behavioral disorders, and language impairment among second-grade children. J Child Psychol Psychiatry. 2000; 41:473-482.

41. Hart KI, Fujiki M, Brinton B, Hart CH. The relationship between social behavior and severity of language impairment. $J$ Speech Lang Hear Res. 2004;47:647-662.

42. Corey DM, Hurley MM, Foundas AL. Right and left handedness defined: a multivariate approach using hand preference and hand performance measures. Neuropsychiatry Neuropsychol Behav Neurol. 2001;14:144-152.

43. Adamo DE, Taufiq A. Establishing hand preference: why does it matter? Hand (N Y). 2011;6:295-303.

44. Johnston RB, Stark RE, Mellits ED, Tallal P. Neurological status of language-impaired and normal children. Ann Neurol. 1981;10: 159-163.

45. de Guibert C, Maumet C, Jannin P, et al. Abnormal functional lateralization and activity of language brain areas in typical specific language impairment (developmental dysphasia). Brain. 2011;134:3044-3058.

46. O’Callaghan MJ, Burn YR, Mohay HA, Rogers Y, Tudehope DI. The prevalence and origins of left hand preference in high risk infants, and its implications for intellectual, motor and behavioural performance at four and six years. Cortex. 1993;29: 617-627. 
47. Whitehouse AJ, Mattes E, Maybery MT, et al. Sex-specific associations between umbilical cord blood testosterone levels and language delay in early childhood. J Child Psychol Psychiatry. 2012; 53:726-734.

48. Shaywitz SE, Shaywitz BA, Fletcher JM, Escobar MD. Prevalence of reading disability in boys and girls. Results of the Connecticut Longitudinal Study. J Am Med Assoc. 1990;264: 998-1002.

49. Crespo-Eguílaz N, Narbona J. Subtipos de trastorno específico del desarrollo del lenguaje: perfiles clínicos en una muestra hispanohablante. Rev Neurol. 2006;43: S193-S200.

50. Bishop DV, Hayiou-Thomas ME. Heritability of specific language impairment depends on diagnostic criteria. Genes Brain Behav. 2008;7:365-372.

51. Beitchman JH, Brownlie EB, Inglis A, et al. Seven-year follow-up of speech/language impaired and control children: psychiatric outcome. J Child Psychol Psychiatry. 1996;37:961-970.

52. Lindsay G, Dockrell J. The behaviour and self-esteem of children with specific speech and language difficulties. Br J Educ Psychol. 2000;70(pt 4):583-601.

53. Bishop DV. Uncommon Understanding: Development and Disorders of Language Comprehension in Children. East Sussex, UK: Psychology Press, Taylor \& Francis Group; 1997.

54. Conti-Ramsden G, Botting N. Emotional health in adolescents with and without a history of specific language impairment (SLI). J Child Psychol Psychiatry. 2008;49:516-525.

55. Zubrick SR, Taylor CL, Rice ML, Slegers DW. Late language emergence at 24 months: an epidemiological study of prevalence, predictors, and covariates. J Speech Lang Hear Res. 2007;50: 1562-1592.
56. Bishop DV, North T, Donlan C. Nonword repetition as a behavioural marker for inherited language impairment: evidence from a twin study. J Child Psychol Psychiatry. 1996;37:391-403.

57. Conti-Ramsden G, Simkin Z, Botting N. The prevalence of autistic spectrum disorders in adolescents with a history of specific language impairment (SLI). J Child Psychol Psychiatry. 2006;47:621-628.

58. Paul R, Cohen DJ. Outcomes of severe disorders of language acquisition. J Autism Dev Disord. 1984;14:405-421.

59. Paul R, Cohen DJ, Caparulo BK. A longitudinal study of patients with severe developmental disorders of language learning. $J \mathrm{Am}$ Acad Child Psychiatry. 1983;22:525-534.

60. Reisinger LM, Cornish KM, Fombonne E. Diagnostic differentiation of autism spectrum disorders and pragmatic language impairment. J Autism Dev Disord. 2011;41:1694-1704.

61. Hagberg BS, Miniscalco C, Gillberg C. Clinic attenders with autism or attention-deficit/hyperactivity disorder: cognitive profile at school age and its relationship to preschool indicators of language delay. Res Dev Disabil. 2010;31:1-8.

62. Loucas T, Charman T, Pickles A, et al. Autistic symptomatology and language ability in autism spectrum disorder and specific language impairment. J Child Psychol Psychiatry. 2008;49: 1184-1192.

63. Verhoeven JS, Rommel N, Prodi E, et al. Is there a common neuroanatomical substrate of language deficit between autism spectrum disorder and specific language impairment? Cereb Cortex. 2012;22:2263-2271.

64. Nelson HD, Nygren P, Walker M, Panoscha R. Screening for speech and language delay in preschool children: systematic evidence review for the US Preventive Services Task Force. Pediatrics. 2006;117: e298-e319. 